ISSN: $2594-4827$

\title{
A PRESENÇA DOS CONHECIMENTOS INDÍGENAS NO AMBIENTE EDUCACIONAL FORMAL: O QUE PENSAM OS ALUNOS?
}

\author{
Fabrício Gurkewicz Ferreira ${ }^{1}$ \\ Lediane Fani Felzke ${ }^{2}$
}

\section{RESUMO}

Esse artigo é o resultado da análise dos entendimentos que um grupo de alunos do curso Técnico em Informática Integrado ao Ensino Médio do Instituto Federal de Rondônia (IFRO), campus Ji-Paraná, possui a respeito da temática indígena no âmbito escolar, em especial as suas corporalidades, e a sua presença na disciplina de Educação Física. Para o percurso metodológico foi escolhida a pesquisa de natureza qualitativa e caráter exploratório. Como resultado de nossas análises verificamos que os alunos reconhecem a importância do estudo dos conhecimentos indígenas e de sua viabilidade nas aulas de Educação Física bem como desconhecem a compreensão desses povos a respeito de suas corporalidades e tiveram pouco contato com conteúdos que se relacionavam com as culturas indígenas em sua vida escolar.

Palavras-chave: Conhecimentos indígenas; educação física; corporalidades.

\section{ABSTRACT}

This article is the result of the analysis of enterprises that a group of students of the Technician in Informatics Integrated to the High School of the Federal Institute of Rondônia (IFRO), campus Ji-Paraná, has about the indigenous theme in the school curriculum, in as their corporalities, and their presence in the Physical Education Subject. For the methodological screening, a qualitative and exploratory research was chosen. As a result of our research students recognize the importance of studying indigenous

\footnotetext{
${ }^{1}$ Professor EBTT do IFRO Ji-Paraná. Mestrando do programa ProfEPT do IFRO - Campus Porto Velho Calama, fabricio.gurkewicz@ifro.edu.br

2 Doutora em Antropologia. Docente do programa ProfEPT do IFRO - Campus Porto Velho Calama, lediane.fani@ifro.edu.br
} 
knowledge and its feasibility in Physical Education classes. However, we are unaware of the understanding of these people about their own corporalities once they have had little contact with content that are related to indigenous cultures in their school life

Keywords: Indigenous knowledges; Physical Education; corporalities.

\section{INTRODUÇÃO}

O presente artigo apresenta resultados parciais de uma pesquisa em andamento vinculada ao Mestrado Profissional em Educação Profissional e Tecnológica - ProfEPT, realizado no Instituto Federal de Rondônia, campus Calama. Investigamos aqui a percepção que os alunos de uma turma do curso Técnico em Informática Integrado ao Ensino Médio do Instituto Federal de Rondônia (IFRO), campus Ji-Paraná, possuem a respeito da presença de conhecimentos oriundos das culturas indígenas no ambiente escolar. Esta compreensão está estruturada no contato que eles tiveram com os conhecimentos indígenas durante a sua vida escolar, na possibilidade desses saberes serem inseridos na disciplina de Educação Física e as contribuições que o estudo das corporalidades indígenas podem lhes proporcionar.

A efetivação do estudo da temática indígena nas escolas deveria estar entre as prioridades das políticas públicas voltadas para a educação. Conhecer os costumes, o modo de organização e a história dos povos indígenas é indispensável para que hajamos com respeito e valorizemos os povos originários do nosso país. Uma das tentativas de concretizar a sua participação no espaço escolar, foi a lei $11.645 / 08$, que tornou obrigatório o estudo da história e da cultura afro-brasileira e indígena. Entretanto, o que se percebe ao analisar a realidade escolar é a necessidade de ainda percorrer um longo caminho para que isso, de fato, aconteça.

Bergamaschi e Gomes (2012) ressaltam os esforços que os povos indígenas fazem para que aconteça um diálogo intercultural. Nesse sentido, as autoras acreditam ser preciso que a escola também se esforce para estabelecer esse intercâmbio cultural, a partir do trato com as histórias e as culturas desses povos. Dessa forma, tornar-se-á possível a 
superação da invisibilidade histórica vivenciada pelas sociedades indígenas através da afirmação de sua presença.

O modo como o corpo é entendido dentro das culturas indígenas brasileiras, ou seja, as suas corporalidades, constitui-se uma ponte interessante para que os saberes das etnias possam se fazer presentes na escola. As pinturas, os rituais, as danças, os jogos, os esportes, dentre outras práticas que se valem da utilização do corpo, propiciam-nos uma representação da riqueza e da diversidade dos conhecimentos indígenas.

Para Grando (2004), o corpo, nas sociedades indígenas brasileiras, possui um papel fundamental para o entendimento de toda a organização social, mitológica e cultural de uma etnia. Nessa perspectiva, compreender as idiossincrasias de um povo passa pela análise de como ocorre as intervenções corporais em cada fase da vida, respeitando as especificidades culturais e históricas de cada contexto.

A inclusão dos conhecimentos oriundos das culturas indígenas no ambiente escolar, em especial as suas corporalidades, parece-nos legítima. Isso posto, iremos verificar neste artigo em que medida o pensamento de um grupo de alunos se aproxima dessa compreensão. Antes, porém, iremos tecer algumas reflexões a respeito do entendimento sobre o corpo em nossa sociedade, a sua importância nas sociedades indígenas e como isso torna o seu estudo relevante no ambiente escolar.

\section{REFLEXÕES SOBRE O CORPO E A SUA IMPORTÂNCIA PARA OS AMERÍNDIOS}

O corpo, que foi fonte de intensos debates em diversas civilizações ao longo da história, ainda hoje centraliza estudos e pesquisas a respeito de suas manifestações, implicações e representatividade em um contexto social, em razão de ser portador das marcas, dos símbolos, dos desejos e das inquietações de determinada coletividade (BARBOSA; MATOS; COSTA, 2011). Assim, compreender o processo de construção de um corpo possibilita entender a sociedade em que ele está inserido.

No corpo evidencia-se a aquisição dos sentidos e significados de determinado agrupamento social, em que por meio da imitação, os comportamentos são analisados e validados pelos indivíduos, ao mesmo tempo em que promove a sua integração. A sua concepção transita por diversas dimensões da experiência humana, sendo que a sua forma de se manifestar está relacionada com as experiências vivenciadas junto a familiares, 
grupos de trabalho, religiosidade etc., onde atua como produtor de cultura e também é produzido por ela (GRANDO, 2004).

Do mesmo modo que as sociedades atuais são complexas, o corpo, como resultado de uma construção social, também o é. Isto se dá pelo que fato de que cada contexto social influi no corpo de uma maneira particular e, apesar de cada pessoa compor uma identidade singular, esta se configura de uma maneira específica com um determinado grupo e uma determinada sociedade. Assim, o modo como cada corpo estabelece as suas relações e se apropria de suas experiências será único (GRANDO, 2014).

Caracterizado, então, por sua complexidade, o corpo é um meio produtor de sentidos, os quais são construídos por meio das relações estabelecidas com outros corpos em um mundo dinâmico de natureza simbólica, sendo que este atributo também diz respeito ao próprio corpo. Os fatores dentro de um determinado contexto sociocultural que intervém no corpo de uma pessoa são diversos, tais como a representatividade que possui ou não dentro da família, as expectativas e oportunidades que lhe cercam, o acesso a bens culturais e econômicos, e as implicações que isto terá nas relações que estabelece com o meio ao seu redor (ibidem.).

O corpo só se individualiza dentro do contexto em que está inserido a partir do momento em que estabelece vínculos e constrói sentidos nesse processo, participando de forma efetiva da vida coletiva e constituindo uma identidade que o torna reconhecido no grupo ao qual pertence. Antes disso, como no momento em que nasce, o corpo é social e não individual.

Não há uma única forma correta de constituir-se ou compreender-se como corpo no mundo, o seu entendimento estará vinculado às experiências às quais a pessoa foi submetida durante toda a sua vida, pois as dimensões que compõe o corpo são produzidas dentro de uma cultura e podem viabilizar a sua integração ou exclusão em uma sociedade (ibidem.).

De acordo com Daolio (2013, p.36) "no corpo estão inscritos todas as regras, todas as normas e todos os valores de uma sociedade específica, por ser ele o meio de contato primário do indivíduo que o cerca". Podemos percebê-lo como socialmente concebido e uma análise de sua representação social oferece-nos uma sociedade em particular. Nesse sentido, cada agrupamento social determina um conjunto de qualidades que cada pessoa deve apresentar, seja do ponto de vista físico, intelectual ou moral. 
O corpo não é um recipiente vazio em que a cultura o preenche totalmente. Ele é fruto da interação entre corpo e cultura. Portanto, é essencial que compreendamos quais princípios, normas, valores levam um corpo a se manifestar daquela forma, ou seja, quais símbolos culturais estão presentes para que assim se manifeste, posto que, mais importante do que as semelhanças que definem o corpo humano, é a forma como os seus conceitos e as suas definições são construídas dentro de cada cultura (DAOLIO, 2013).

Tendo consciência ou não, todo homem possui influências culturais no seu corpo, sendo que não existe um que seja melhor ou pior. Existem apenas corpos diferentes, que foram forjados ao longo dos tempos, em cada sociedade, de acordo com as suas peculiaridades culturais. Nessa perspectiva, há aqueles vinculados a sociedade ocidental, de caráter individualista, em que o corpo é dissociado da pessoa (LE BRETON, 2011).

Por outro lado, há também a noção de corpo constituída junto às sociedades tradicionais, de cunho holístico, nas quais o corpo não está apenas atrelado à pessoa, mas também à natureza e ao cosmos. Dentre as diversas sociedades tradicionais, as sociedades indígenas brasileiras representam importante fonte de estudo a respeito da corporalidade, principalmente após o estudo basilar de Viveiros de Castro, Seeger e Da Matta (1979), que trata da noção de corpo desses povos como um elemento central para o entendimento de toda a sua organização.

De acordo com Viveiros de Castro, Seeger e Da Mata (1979, p. 7) "A fabricação, decoração, transformação e destruição dos corpos são temas em torno dos quais giram mitologias, a vida cerimonial e a organização social". Os corpos, nessas coletividades, são utilizados como instrumentos, para que os valores, símbolos e tradições de sua cultura permaneçam vivos e continuem a ser propagados através das próximas gerações.

Para que estes corpos estejam de acordo com as necessidades de sua etnia, eles passam por um processo de "fabricação" que se inicia desde antes do seu nascimento e prossegue até a sua morte. Neste processo, o corpo sofre intervenções sistemáticas que possibilitam ao indivíduo ser reconhecido pelo seu próprio grupo e também pelos outros. Essa "fabricação" não é apenas do corpo, mas também da pessoa, uma vez que não há uma cisão entre corpo e pessoa nessas sociedades (GRANDO, 2004).

A "fabricação" do corpo acontece a partir da elaboração e transmissão das técnicas corporais de cada grupo étnico e se desenvolve nas relações do cotidiano. Pelo fato de cada técnica estar relacionada com meio social em que ela se originou, a sua compreensão 
necessita do entendimento deste contexto. Toda técnica assimilada pelo corpo, torna-se parte constituinte da identidade da pessoa em um processo que ocorre de forma consciente ou inconsciente (GRANDO, 2004).

A técnica corporal é um conceito desenvolvido pelo sociólogo francês Marcel Mauss e diz respeito a forma como cada sociedade se apropria do seu corpo, por meio de seus gestos, tais como o modo de andar, de nadar, de comer, dentre outros (MAUSS, 1974). Um dos pontos importantes do trabalho de Mauss é aquele que nos permite compreender o corpo e os movimentos humanos como símbolos, já que são entendidos como práticas sociais, as quais possuem uma tradição, que são passadas de geração em geração, permitindo que os movimentos de andar, da postura, técnicas esportivas, dentre outras, possam se perpetuar dentro dos agrupamentos sociais (DAÓLIO, 2013).

$\mathrm{Na}$ construção do seu entendimento a respeito das técnicas corporais e de como a sua perpetuação ocorre por meio de ações educativas que variam de acordo com cada sociedade, podendo, inclusive, influenciar outros agrupamentos sociais, Mauss (1974) se vale de alguns movimentos corporais para ilustrar as suas ideias, como por exemplo o andar. Segundo ele, ao permanecer internado em um hospital em Nova Iorque, percebeu que já havia visto aquela forma de andar das enfermeiras, lembrando, posteriormente, que foi no cinema. Contudo, ao retornar a Paris, verificou que as jovens francesas também estavam andando do mesmo modo, concluindo que a influência americana do andar havia chegado através do cinema e que, portanto, esse movimento não era resultado de um conjunto de mecanismos de cada indivíduo, mas um produto de influência social.

Portanto, para Mauss (1974, p. 405) “É precisamente nessa noção de prestígio da pessoa que faz o ato ordenado, autorizado, provado em relação ao indivíduo imitador, que se verifica todo elemento social. No ato imitador que se segue, verificam-se o elemento psicológico e o elemento biológico". Isso se torna mais perceptível, ao observar o processo de assimilação e repetição das técnicas corporais por parte das crianças. A criança, assim como o adulto, busca reproduzir atos bem-sucedidos por pessoas nas quais confia e que possuem ascendência sobre ela. Isso também acontece em atos de caráter biológico, como as relativas ao corpo. Desse modo, a criança agrega uma série de movimentos, os quais são realizados diante dela ou com ela por pessoas que desfrutam de sua deferência. 
Com base no entendimento sobre as técnicas corporais, podemos concluir que a partir da observação da gesticulação e da postura corporal, é possível adivinhar a origem da pessoa devido às particularidades corporais presentes em cada cultura. Nas sociedades indígenas, este fato é ainda mais nítido, posto que é fundamental para os indivíduos de uma etnia serem reconhecidos pelo seu próprio grupo e pelos demais.

Nesse sentido, em diferentes momentos da vida do indivíduo tais como o nascimento, a puberdade, o casamento e a morte, em que ele está sendo moldado de acordo com as características do seu grupo; percebe-se a "educação do corpo". Por meio de intervenções corporais, acontece a transformação da pessoa e ela passa a ser reconhecida pelo grupo e integrada junto a ele (GRANDO, 2004).

Ainda sobre o entendimento do corpo dos povos indígenas, Grando (2004, p. 60) nos diz que "[...] para entendermos a corporalidade indígena devemos ter claro que o corpo não é em si uma totalidade, mas manifesta-se como totalidade enquanto pessoa que é produto cultural simbólico de todo um conjunto de práticas corporais vivenciadas coletivamente". O corpo e a pessoa só são percebidos enquanto totalidade a partir do momento em que são validados pelo seu grupo mediante a um conjunto de intervenções corporais.

As corporalidades indígenas, que representam saberes essenciais referentes às etnias, devido a sua presença nos diferentes aspectos que permeiam a organização desses povos, tais como, a cosmologia, os rituais e os modos de produção, dentre outros; possibilitam-nos a compreensão do funcionamento de toda a sua estrutura. Destarte, ao realizar estudos sobre os povos indígenas, sobretudo nas escolas, torna-se relevante tratar das concepções ameríndias acerca do corpo e da construção da pessoa. Contudo, para levar a cabo tal empreitada, compete-nos inicialmente averiguar quais as noções dos alunos a respeito deste tema. Em especial, o que pensam os alunos do grupo em questão? Como observam a importância dos conhecimentos indígenas de uma maneira geral? $\mathrm{O}$ que opinam diante da inserção de tais conhecimentos na disciplina de Educação Física? A seguir, procuraremos elucidar essas questões.

\section{METODOLOGIA}

A presente pesquisa é de natureza qualitativa e caráter exploratório. Para Chizzotti (2008), as pesquisas qualitativas são aquelas nas quais o objetivo é interpretar os sentidos 
de determinado fenômeno, por meio dos significados atribuídos pelas pessoas ao que falam ou fazem, valendo-se para isso, do uso, ou não, de quantificações. Triviños (1987) nos diz que os estudos exploratórios são aqueles que permitem ao pesquisador aumentar o seu conhecimento sobre determinado tema. Busca-se a aproximação de um determinado fato, para se construir uma visão mais ampla.

Os dados apresentados nesse artigo, coletados por meio de um questionário, referem-se aos primeiros passos de uma pesquisa de mestrado que tem por objetivo analisar a contribuição que o estudo das corporalidades indígenas podem proporcionar a estudantes de uma escola não indígena. A amostra é composta por trinta e cinco alunos, de ambos os sexos, de uma turma de terceiro ano do curso Técnico em Informática Integrado ao Ensino Médio do Instituto Federal de Rondônia (IFRO), campus Ji-Paraná.

O questionário foi aplicado entre os meses de março e abril de 2019 e diz respeito a primeira intervenção da pesquisa. A sua aplicação teve por objetivo fazer um diagnóstico inicial a respeito dos conhecimentos que os alunos possuíam acerca do tema para que o planejamento das aulas a serem desenvolvidas posteriormente atendesse às necessidades apresentadas pelos alunos e, destarte, proporcionar um processo de ensino aprendizagem mais exitoso.

As questões dizem respeito ao contato que os alunos tiveram com os conhecimentos indígenas, sobretudo com as suas práticas corporais, no âmbito escolar; e a percepção que detém a respeito das concepções ameríndias sobre o corpo. Foram ao todo nove questões abertas. Destas, sete possuem respostas dicotômicas (sim ou não) além da justificativa. A apresentação será feita através de quadros que contém o tema da pergunta, o conjunto de respostas por aproximação, o valor absoluto (V.a.) e a porcentagem (\%) de cada uma das respostas. Em seguida, procedemos uma análise tendo como referência estudos presentes na literatura científica.

\section{RESULTADOS E DISCUSSÕES}

\section{A PERCEPÇÃO DOS ALUNOS SOBRE OS ESTUDOS DOS CONHECIMENTOS INDÍGENAS}


Quadro 1 - Estudo dos conhecimentos indígenas durante a vida escolar

\begin{tabular}{|l|l|l|l|}
\hline \multicolumn{2}{|l|}{ Conjunto de respostas } & V.a. & $\%$ \\
\hline \multirow{3}{*}{ Sim } & Aspectos gerais das culturas indígenas & $\mathbf{7}$ & $\mathbf{2 0}$ \\
\cline { 2 - 4 } & Conhecimentos indígenas relacionados à Geografia & $\mathbf{2}$ & $\mathbf{5 , 7}$ \\
\cline { 2 - 5 } & A organização social de etnias indígenas de Rondônia & $\mathbf{2}$ & $\mathbf{5 , 7}$ \\
\hline Não & & $\mathbf{2 4}$ & $\mathbf{6 8 , 6}$ \\
\hline
\end{tabular}

Fonte: Questionário aplicado pelos autores, 2019.

De acordo com o quadro 1, podemos perceber que 68,6\% dos alunos não tiveram contato com os conhecimentos das culturas indígenas até o momento, visto que dos trinta e cinco participantes, apenas onze deram resposta afirmativa.

Por outro lado, como pode ser observado nas respostas em destaque, aqueles que tiveram a oportunidade de estudar, não tiveram a sua vivência restrita a uma área do conhecimento. De maneira específica, podemos verificar a menção a disciplina de Geografia. Mas, a referência ao estudo dos aspectos gerais das culturas indígenas e a sua organização social, leva-nos a crer que outras disciplinas também desenvolveram esses conhecimentos. Isto é um fato importante, pois, embora a lei 11.645/08 aponte que, em especial, o trato com esses saberes deverá ser feito pelas áreas de Educação Artística e de Literatura e História brasileiras, é fundamental, pela complexidade da temática, que haja a participação de todas as áreas, seja de forma disciplinar ou interdisciplinar (RUSSO; PALADINO, 2014).

A maior parte dos participantes consideram relevante o estudo, tendo em vista apenas cinco respostas negativas dentre as trinta e cinco. Em relação a uma das justificativas presentes nas respostas negativas, notamos o seu vínculo a um pensamento que predominou durante muito tempo no Ensino Médio, sobretudo em instituições que também desenvolviam de forma integrada ou concomitante a Educação Profissional, que é o foco no mercado de trabalho (RAMOS, 2008). 
Quadro 2 - A importância do estudo dos conhecimentos indígenas

\begin{tabular}{|l|l|l|l|}
\hline \multicolumn{2}{|l|}{ Conjunto de respostas } & V.a. & $\%$ \\
\hline \multirow{4}{*}{ Sim } & Por contribuírem na formação do nosso país & $\mathbf{7}$ & $\mathbf{2 0}$ \\
\cline { 2 - 4 } & Para aprender sobre outras culturas presentes no nosso país & $\mathbf{1 6}$ & $\mathbf{4 5 , 7}$ \\
\cline { 2 - 4 } & Pela presença desses povos em nossa região & $\mathbf{4}$ & $\mathbf{1 1 , 4}$ \\
\cline { 2 - 4 } & Para obter novos conhecimentos & $\mathbf{3}$ & $\mathbf{8 , 6}$ \\
\hline Não & Não Sabem & $\mathbf{4}$ & $\mathbf{1 1 , 4}$ \\
\hline & Não se relaciona com a futura profissão & $\mathbf{1}$ & $\mathbf{2 , 9}$ \\
\hline
\end{tabular}

Fonte: Questionário aplicado pelos autores, 2019.

No que concerne às respostas positivas em destaque, é interessante notar a presença de diferentes justificativas para respaldar as opiniões. Além disso, podemos inferir a respeito desses saberes que, embora tenham a sua presença garantida no ambiente escolar em razão da lei 11.645/08, possuem legitimidade, haja vista a sua contribuição na bagagem de conhecimentos dos alunos e no respeito intercultural (DOMINGOS JUNIOR et al., 2017; TENORIO; LOPES DA SILVA, 2014a).

Nas respostas em destaque, observamos diferentes fatores. No entanto, de um modo geral, representam a falta de importância dada ao tema e, que assim como em outros trabalhos, pode ser constatado tanto pelas poucas ações executadas no âmbito escolar (PEREIRA et al., 2018), quanto por políticas públicas ineficientes (SILVA, 2012), ou também, pelo total desconhecimento das culturas indígenas dentro e fora do espaço escolar (KEMPE; CHASSOT, 2017).

Quadro 3 - Fatores que limitam a presença dos conhecimentos indígenas no ambiente escolar

\begin{tabular}{|l|l|l|}
\hline Conjunto de respostas & V.a. & \% \\
\hline Por ser um conteúdo irrelevante socialmente & $\mathbf{1 1}$ & $\mathbf{3 1 , 4}$ \\
\hline $\begin{array}{l}\text { Em razão da formação escolar ser voltada para o mercado de } \\
\text { trabalho }\end{array}$ & $\mathbf{4}$ & $\mathbf{1 1 , 4}$ \\
\hline
\end{tabular}




\begin{tabular}{|l|l|l|}
\hline Por serem conhecimentos que sofrem discriminação & $\mathbf{7}$ & $\mathbf{2 0}$ \\
\hline Falta de conhecimento dos professores & $\mathbf{5}$ & $\mathbf{1 4 , 3}$ \\
\hline Pela não divulgação dos conhecimentos sobre os povos indígenas & $\mathbf{2}$ & $\mathbf{5 , 7}$ \\
\hline Espaço insuficiente na grade curricular & $\mathbf{1}$ & $\mathbf{2 , 9}$ \\
\hline Não sabem & $\mathbf{5}$ & $\mathbf{1 4 , 3}$ \\
\hline
\end{tabular}

Fonte: Questionário aplicado pelos autores, 2019.

\section{Quadro 4 - A presença dos conhecimentos indígenas na disciplina de Educação} Física

\begin{tabular}{|l|l|l|l|}
\hline \multicolumn{2}{|l|}{ Conjunto de respostas } & V.a. & $\%$ \\
\hline \multirow{4}{*}{ Sim } & Para conhecer novas práticas esportivas & $\mathbf{8}$ & $\mathbf{2 2 , 8}$ \\
\cline { 2 - 4 } & A fim de conhecermos as suas práticas corporais & $\mathbf{6}$ & $\mathbf{1 7 , 1}$ \\
\cline { 2 - 4 } & Com o propósito de conhecermos as suas culturas & $\mathbf{6}$ & $\mathbf{1 7 , 1}$ \\
\cline { 2 - 4 } & Pois eles realizam atividades físicas & $\mathbf{4}$ & $\mathbf{1 1 , 4}$ \\
\cline { 2 - 4 } & Tem as danças & $\mathbf{1}$ & $\mathbf{2 , 9}$ \\
\cline { 2 - 4 } & Há atividades interessantes & $\mathbf{5}$ & $\mathbf{1 4 , 3}$ \\
\cline { 2 - 4 } & Pode estar em todas as disciplinas escolares & $\mathbf{1}$ & $\mathbf{2 , 9}$ \\
\cline { 2 - 4 } & Tem os jogos & $\mathbf{1}$ & $\mathbf{2 , 9}$ \\
\hline Não & Pois não é objeto de estudo da disciplina & $\mathbf{3}$ & $\mathbf{8 , 6}$ \\
\hline
\end{tabular}

Fonte: Questionário aplicado pelos autores, 2019.

Como verificado no quadro, somente três respostas foram negativas. A afirmação de que esses conhecimentos não fazem parte do currículo da disciplina, instiga-nos a algumas reflexões. Kempe e Chassot (2017) nos dizem que muitas práticas corporais indígenas são realizadas pelos indivíduos na sociedade não indígena, mas com denominações diferentes. Nessa perspectiva, Domingos Junior et al. (2017) ao desenvolverem aulas com turmas de $9^{\circ}$ ano em uma escola particular na cidade de Natal$\mathrm{RN}$, perceberam que os alunos conheciam alguns elementos das culturas indígenas, mas 
não sabiam que estava vinculado a esses povos. Outro ponto que ajuda a reforçar essa situação, como ressalta Pereira et al. (2018), é o fato de os próprios professores não conseguirem estabelecer uma associação entre a sua área de conhecimento e esse tema.

Em relação às respostas afirmativas, são pertinentes algumas considerações a respeito da presença do elemento esportivo. Historicamente, o esporte é o conteúdo hegemônico na disciplina de Educação Física (CASTELLANI FILHO, 1991; COLETIVO DE AUTORES, 1992). Esse fato faz com que ele seja o conteúdo mais desejado nas aulas e, mesmo quando são ofertadas outras temáticas, a competitividade, um dos princípios fundamentais do esporte, tem que estar presente. Isso nos é demonstrado por Domingos Junior et al. (2017) ao tematizar os jogos dos povos indígenas junto a alunos do ensino fundamental que, não obstante a satisfação dos alunos em vivenciarem aquela experiência, ainda assim queriam ser a pessoa ou a equipe que venceu.

\section{Quadro 5 - Práticas corporais indígenas conhecidas}

\begin{tabular}{|l|l|l|l|}
\hline \multicolumn{2}{|l|}{ Conjunto de respostas } & V.a. & $\%$ \\
\hline \multirow{4}{*}{ Sim } & Pinturas corporais & 2 & 5,7 \\
\cline { 2 - 4 } & A prática do arco e flecha & 2 & 5,7 \\
\cline { 2 - 4 } & Corrida com tora & 1 & $\mathbf{2 , 9}$ \\
\cline { 2 - 4 } & Dança & 2 & $\mathbf{5 , 7}$ \\
\cline { 2 - 4 } & A prática da caça & $\mathbf{2}$ & $\mathbf{5 , 7}$ \\
\cline { 2 - 4 } & Rituais & $\mathbf{2}$ & $\mathbf{5 , 7}$ \\
\hline Não & Não conhecem & $\mathbf{2 4}$ & $\mathbf{6 8 , 6}$ \\
\hline
\end{tabular}

Fonte: Questionário aplicado pelos autores, 2019.

Constatamos que $68 \%$ dos alunos não possuía conhecimento a respeito das práticas corporais indígenas, tendo em vista as vinte e quatro respostas negativas. Dentre as afirmativas, notamos, no quadro 5, uma variedade de práticas nas menções. Isso demonstra que, um terço dos estudantes avaliados demonstraram conhecimentos em relação a diversidade presente na cultura corporal dos povos indígenas. Além disso, essas 
manifestações são imbuídas de valores e significados, os quais, muitas vezes, não são encontrados no contexto social capitalista (TENORIO; LOPES DA SILVA, 2014b).

\section{Quadro 6 - Práticas corporais indígenas vivenciadas}

\begin{tabular}{|l|l|l|l|}
\hline \multicolumn{2}{|l|}{ Conjunto de respostas } & V.a. & $\%$ \\
\hline \multirow{4}{*}{ Sim } & Pinturas corporais & 2 & 5,7 \\
\cline { 2 - 5 } & Futebol & 1 & $\mathbf{2 , 9}$ \\
\cline { 2 - 5 } & Alguns esportes indígenas & 1 & $\mathbf{2 , 9}$ \\
\cline { 2 - 5 } & Dança & 1 & $\mathbf{2 , 9}$ \\
\hline \multirow{2}{*}{ Não } & Não conhecem & $\mathbf{3 0}$ & $\mathbf{8 5 , 6}$ \\
\hline
\end{tabular}

Fonte: Questionário aplicado pelos autores, 2019.

Como era de se esperar pelas respostas à pergunta anterior, $85 \%$ os alunos não tiveram alguma vivência, sendo que apenas 14,4 responderam de forma afirmativa. Dentre essas, uma que chama a atenção é a alusão ao futebol. A sua menção pode estar relacionada com o desconhecimento sobre a história dessa prática ou estar se referindo ao Jikunahati, uma variante do futebol jogado exclusivamente com a cabeça pela etnia Paresi. Em todo caso, reforça o que já foi apresentado anteriormente, que é a representatividade das práticas esportivas para os alunos.

Outra prática citada e que possui relevância dentro das sociedades indígenas é a dança. O seu uso, em muitas etnias, é voltado para a educação dos membros, como nos mostra Grando (2005), que ao buscar compreender os sentidos e significados que as práticas corporais têm para os Bororo, verificou que além de estar presente nos rituais e festas daquele povo, detém um papel fundamental no processo educativo dos indivíduos, por meio da transmissão de valores, de técnicas corporais e da compreensão de sua função dentro da organização social.

Em $77 \%$ das respostas é mencionado o desconhecimento sobre como os povos indígenas entendem o corpo. Em relação aos apontamentos que procuraram refletir a respeito, podemos notar certa superficialidade nas ideias. O que não demonstra a relevância que o corpo possui nas sociedades indígenas, em especial as brasileiras, pois 
as intervenções realizadas no e sobre o corpo perpassam toda a sua organização sociocultural (VIVEIROS DE CASTRO; SEEGER; DA MATTA, 1978). Ou seja, o corpo é um elemento central na organização desses povos.

Quadro 7 - O entendimento sobre o corpo dos povos indígenas

\begin{tabular}{|l|l|l|}
\hline Conjunto de respostas & V.a. & \% \\
\hline $\begin{array}{l}\text { Instrumento utilizado para perpetuação dos conhecimentos da } \\
\text { etnia }\end{array}$ & $\mathbf{2}$ & $\mathbf{5 , 7}$ \\
\hline Algo que permite a expressão dos seus sentimentos & $\mathbf{1}$ & $\mathbf{2 , 9}$ \\
\hline O corpo possui relação com o sagrado & $\mathbf{1}$ & $\mathbf{2 , 9}$ \\
\hline Eles possuem conhecimentos variados & $\mathbf{3}$ & $\mathbf{8 , 6}$ \\
\hline O corpo se relaciona com a natureza & $\mathbf{1}$ & $\mathbf{2 , 9}$ \\
\hline Não sabem & $\mathbf{2 7}$ & $\mathbf{7 7}$ \\
\hline
\end{tabular}

Fonte: Questionário aplicado pelos autores, 2019.

Além disso, embora cada etnia possua organização econômica e social própria, assim como, práticas corporais peculiares, os corpos, dentro das sociedades indígenas brasileiras, são construídos para se tornarem seres coletivos, por meio de um processo em que são inscritos valores, costumes, normas sociais e comportamentos desejáveis por aquele meio em que o indivíduo está inserido (ALMEIDA; SUASSUNA; GRANDO, 2010).

Quadro 8 - Diferenças entre o entendimento sobre o corpo dos povos indígenas e dos povos não-indígenas

\begin{tabular}{|l|l|l|l|}
\hline \multicolumn{2}{|l|}{ Conjunto de respostas } & V.a. & $\%$ \\
\hline \multirow{3}{*}{ Sim } & $\begin{array}{l}\text { Pois os povos indígenas possuem uma relação mais } \\
\text { profunda com corpo }\end{array}$ & $\mathbf{3}$ & $\mathbf{8 , 6}$ \\
\cline { 2 - 4 } & Em razão de cada povo ter as suas peculiaridades culturais & $\mathbf{1 7}$ & $\mathbf{4 8 , 6}$ \\
\hline
\end{tabular}


ISSN: $2594-4827$

\begin{tabular}{|l|l|l|l|}
\hline & $\begin{array}{l}\text { Em virtude do desenvolvimento científico, os povos não- } \\
\text { indígenas têm mais conhecimento }\end{array}$ & $\mathbf{4}$ & $\mathbf{1 1 , 4}$ \\
\hline Não Sei & $\mathbf{1 1}$ & $\mathbf{3 1 , 4}$ \\
\hline
\end{tabular}

Fonte: Questionário aplicado pelos autores

Um percentual de $31,4 \%$ dos alunos acredita que as visões sobre o corpo, entre os povos indígenas e os povos não indígenas, são diferentes. A respeito dessas diferenças, vale ressaltar a importância dos indivíduos mais velhos da etnia no processo de perpetuação dos conhecimentos sobre o corpo. Grando (2005), ao se referir à educação do corpo que ocorre nas sociedades indígenas, afirma que as ações são conduzidas pelos mais velhos, que transmitem todos os seus saberes aos mais jovens.

\section{Quadro 9 - Contribuições provenientes do estudo das corporalidades indígenas}

\begin{tabular}{|l|l|l|}
\hline Conjunto de respostas & V.a. & $\mathbf{\%}$ \\
\hline Conhecimentos a respeito de suas culturas & $\mathbf{7}$ & $\mathbf{2 0}$ \\
\hline Como obter um condicionamento físico melhor & $\mathbf{3}$ & $\mathbf{8 , 6}$ \\
\hline Estabelecer uma relação de respeito e valorização com o corpo & $\mathbf{1}$ & $\mathbf{2 , 9}$ \\
\hline Diminuir o preconceito a respeito dos povos indígenas & $\mathbf{1}$ & $\mathbf{2 , 9}$ \\
\hline Novos conhecimentos & $\mathbf{8}$ & $\mathbf{2 2 , 8}$ \\
\hline Não sabem & $\mathbf{1 5}$ & $\mathbf{4 2 , 8}$ \\
\hline
\end{tabular}

Fonte: Questionário aplicado pelos autores, 2019.

Dentre as principais respostas obtidas, observamos a citação ao conhecimento a respeito de suas culturas. Isso vai ao encontro do que nos falam Almeida, Suassuna e Grando (2010), que ressaltam o condicionamento cultural pelo qual o indivíduo passa desde o nascimento, em que valores, normas e costumes sociais são insculpidos em sua personalidade. Assim, conhecer a visão sobre o corpo de uma determinada etnia, é conhecer a sua cultura. Grando (2003) vai nessa mesma direção ao assinalar que, as danças dos Bororo, uma manifestação corporal que representam valores e tradições daquele povo, possibilitam, além da integração com a sociedade regional na qual este povo está inserido; o reconhecimento de sua identidade coletiva. 


\section{CONSIDERAÇÕES FINAIS}

Essa pesquisa teve por objetivo verificar o entendimento que alunos do ensino técnico integrado ao médio de uma instituição de Educação Profissional e Tecnológica possuem a respeito dos conhecimentos referentes às culturas indígenas, em especial as suas corporalidades, e a sua inserção no espaço escolar, sobretudo na disciplina de Educação Física. Com base nas respostas apresentadas, podemos afirmar que os alunos reconhecem a importância do estudo dos conhecimentos indígenas e de sua viabilidade nas aulas de Educação Física. No entanto, desconhecem a compreensão desses povos a respeito de suas corporalidades e tiveram pouco contato com conteúdo que se relacionavam com as culturas indígenas em sua vida escolar.

Os conhecimentos limitados que estes alunos tiveram sobre as culturas indígenas indicam-nos que, não obstante a lei 11.645/2008 estar em vigor há mais dez anos, a sua inserção no ambiente escolar tem sido lenta. Estes estudantes tiveram praticamente toda a sua vida escolar sob a abrangência da referida lei e, mesmo assim, atestaram ter pouco conhecimento sobre a temática. Ao nos aproximarmos da realidade escolar, percebemos que, na maioria das vezes, os saberes das culturas indígenas são tratados de forma superficial e pontual, geralmente em datas comemorativas, o que dificulta a processo formativo no sentido do respeito e da valorização da diversidade cultural.

Ao analisarmos o Projeto Pedagógico do Curso (PPC) da instituição em que os alunos estudam atualmente (IFRO, 2017), verificamos a validade dos pressupostos apresentados no parágrafo anterior a respeito do descaso com os conhecimentos das culturas indígenas no ambiente escolar. Embora haja a menção ao trabalho com temas transversais no documento, incluindo a pluralidade cultural, a qual abrangeria os saberes indígenas, tanto nos objetivos gerais quanto nas ementas das disciplinas, não há indícios que sugiram o trabalho com esse tema.

Nesse sentido, a Educação Física pode atuar de forma significativa para o desenvolvimento da temática indígena na escola. Embora a lei supracitada dirija esta tarefa para algumas disciplinas, quais sejam, a Educação Artística, Literatura e História brasileiras, a Educação Física, que tem por objeto de estudo as práticas corporais sistematizadas historicamente pela sociedade, apresenta-se como uma área prolífica para 
o desenvolvimento de ações, tendo em vista a relevância que o corpo possui para os povos indígenas.

As corporalidades, que no contexto indígena, possibilitam-nos entender a sua organização social, a sua cosmologia, os seus rituais, ou seja, permitem que compreendamos minimamente a estrutura e funcionamento sociocultural de uma determinada etnia. Entender o objetivo das diferentes intervenções realizadas no e sobre o corpo é fundamental para que respeitemos e estabeleçamos um diálogo intercultural com povos essenciais na construção da nossa história.

Assim, cientes das limitações dessa pesquisa, que apresenta dados iniciais de uma pesquisa mestrado, queremos ressaltar a importância desse diagnóstico a respeito da presença dos conhecimentos indígenas em âmbito escolar, à medida que nos reforça a urgência para o trato com essa temática, ainda tão negligenciada. Além disso, se pensarmos que as sociedades estão cada vez mais interligadas mundialmente, saber se relacionar interculturalmente se torna indispensável. Ademais, compreender e aprender com o pensamento indígena é primordial para desenvolver relações mais equânimes na sociedade em que todos estamos inseridos.

\section{REFERÊNCIAS}

ALMEIDA, Arthur; SUASSUNA, Dulce; GRANDO, Beleni Saléte. As práticas corporais e a educação do corpo indígena: a contribuição do esporte nos jogos dos povos indígenas. Revista Brasileira de Ciências do Esporte, v. 32, p. 59-74, 2010.

BARBOSA, Maria Raquel; MATOS, Paula Mena; COSTA, Maria Emília. Um olhar sobre o corpo: o corpo ontem e hoje. Psicol. Soc., Florianópolis, v. 23, n. 1, p. 24-34, abr. 2011.

BERGAMASCHI, Maria Aparecida; GOMES, Luana Barth. A temática indígena na escola: ensaios de educação intercultural. Currículo sem Fronteiras, v. 12, p. 53-69, 2012.

CASTELLANI FILHO, Lino. Educação física no Brasil: a história que não se conta. 3. ed. Campinas, SP: Papirus, 1991.

CHIZZOTTI, Antônio. Pesquisa qualitativa em ciências humanas e sociais. 2. ed. Petrópolis RJ: Editora Vozes, 2008. 144p. 
COLETIVO DE AUTORES. Metodologia do ensino de educação física. São Paulo: Cortez, 1992.

DAOLIO, Jocimar. Da cultura do corpo. 17. ed. Campinas, SP: Papirus, 2013.

DOMINGOS JUNIOR, Moaldecir Freire; SILVA, Gustavo Henrique; SALES, Josilane dos Santos; CARLOS, Camila Ursula Batista; SILVA, Luiz Arthur Nunes da. Corpo, cultura de movimento e Jogos Indígenas nas aulas de Educação Física. Cadernos de formação RBCE, v. 8, p. 21-32, 2017.

GRANDO, Beleni Saléte. Corpo e educação: as relações interculturais nas práticas corporais Bororo em Meruri-MT. 2004. 357f. il. Tese (Doutorado em Educação) Programa de Pós-Graduação em Educação, Centro de Ciências da Educação, Universidade Federal de Santa Catarina, Florianópolis, 2004.

Do corpo e da cultura: indícios da realidade na perspectiva intercultural. Rev. Arquivos Em Movimento, Rio de Janeiro, Edição Especial, v.10, n.1, p.138-154, jan/jun 2014.

. Corpo e Cultura: a educação do corpo em relações de fronteiras étnicas e culturais e a constituição da identidade bororo em Meruri-MT. Pensar a Prática, Goiânia-GO, v. 8, n.2, p. 163-179, 2005.

Corpo e Educação: relações interculturais nas práticas corporais bororo em Meruri-MT. Motrivivência, Florianópolis SC, v. Ano XV, n. 20-21, p. 201-209, 2003.

KEMPE, Gédson Cardoso; CHASSOT, Attico Inácio. Práticas corporais indígenas inseridas à Educação Física escolar não indígenas. Revista de Educação Pública, Cuiabá, v.26, n.62/2, p. 549-567, mai./ago.2017.

IFRO. Resolução No 21/REIT - CEPEX/IFRO de 29 de junho de 2017. Dispõe sobre a aprovação da Reformulação do Projeto Pedagógico do Curso Técnico em Informática Integrado ao Ensino Médio do Instituto Federal de Educação, Ciência e Tecnologia de Rondônia - IFRO, Campus Ji-Paraná. Disponível em: https://portal.ifro.edu.br/jiparana/cursos/1999-tecnico-em-informatica-integrado. Acesso em: 29 nov. 2019.

LE BRETON, David. Antropologia do corpo e modernidade. Tradução de Fábio dos Santos Creder. Petrópolis: Vozes, 2011, 405 p.

MAUSS, Marcel. As Técnicas Corporais. In: Sociologia e Antropologia, vol. 2. São Paulo: EPU/EDUSP, 1974.

PEREIRA, Arliene Stephanie Menezes; GOMES, Daniel Pinto; CARMO, Klertianny Teixeira do; MOTA E SILVA, Eduardo Vinicius. Aplicação das leis 10.639/03 e 
11.645/08 nas aulas de educação física: diagnóstico da rede municipal de Fortaleza/CE.

Revista Brasileira de Ciências do Esporte, v. 41, p. 412-418, out./dez. 2019.

RAMOS, Marise Nogueira. Concepção do ensino médio integrado. Texto apresentado em seminário promovido pela Secretaria de Educação do Estado do Pará nos dias 8 e 9 de maio de 2008.

RUSSO, Kelly; PALADINO, Mariana. Reflexões sobre a lei 11.645/2008 e a inclusão da temática indígena na escola. Revista Fórum Identidades, v. 16, p. 15-40, 2015.

SILVA, Maria da Penha da. A diversidade etnico-racial na escola e a temática indígena em questão: discutindo políticas públicas para a efetivação da lei 11.645/08. In:

ENCONTRO DE PESQUISA EDUCACIONAL EM PERNAMBUCO, 4., 2012,

Caruaru. Pesquisa e educação na contemporaneidade: perspectivas teóricometodológicas. Anais [...]. Recife: FUNDAJ, 2012. p. 1-15.

TENORIO, Jederson Garbin; LOPES DA SILVA, Cinthia. Experiência pedagógica com jogos indígenas em aulas de educação física de uma escola pública do estado de Mato Grosso. Instrumento - Revista em estudo e pesquisa em educação, v. 16, p. 279-286, 2014a.

. As práticas corporais indígenas como conteúdo da educação física escolar.

Teoria e Prática da Educação, v. 17, p. 81-91, 2014b.

TRIVIÑOS, Augusto. Introdução à pesquisa em ciências sociais: a pesquisa qualitativa em educação. São Paulo: Atlas, 1987.

VIVEIROS DE CASTRO, Eduardo; SEEGER, Anthony; DA MATTA, Roberto. A construção da pessoa nas sociedades indígenas brasileiras. 1978. (Apresentação de Trabalho/Comunicação). 